\title{
CORPORALIDAD JUVENIL: RETOS PARA LA EDUCACIÓN EN SALUD
}

\begin{abstract}
Resumen
El artículo explora las concepciones del cuerpo asociadas a las percepciones sobre la boca y la salud oral a partir de un estudio realizado con jóvenes estudiantes de Bogotá. A través de este análisis, el autor reflexiona sobre la educación en salud. En este escrito, las concepciones de salud oral se articulan con el desarrollo de la publicidad y de nociones de familia promovidas por saberes expertos y el Estado a través del siglo XX.
\end{abstract}

Palabras clave: Concepción de cuerpo, salud oral, jóvenes

\section{JUVENILE BODYKIND: CHALLENGES FOR THE HEALTH EDUCATION}

\begin{abstract}
This paper explores the body concept connect to perception to mouth and oral health, from to investigation with young students in Bogotá. Across the paper, author thinking the education health. In his analysis, the oral health concept is tying with publicity and family notions that expert and State promoted in twenty-century.
\end{abstract}

Keywords: Body concept, oral health, young people

En el año 2005 se preguntó a los estudiantes de una institución educativa distrital, IED, de Ciudad Bolivar: ¿le darias un beso a alguien que le falta un diente? Como se intentará mostrar, esta pregunta permite un abordaje distinto de la educación en salud. El presente articulo desarrolla las respuestas más relevantes a la pregunta planteada, articula dichas respuestas con la construcción social de la corporalidad y plantea algunos retos para la educación en salud.
La cuestión de darle o no un beso a quien le falta un diente coloca sobre el tapete procesos de subjetivación, es decir, dinámicas de adquisición y/o construcción de principios de visión, de estructuras cognitivas, preferencias y gustos. Estas dinámicas se refieren a la manera como cada uno obtiene una visión de sí mismo, del lugar que ocupa en la sociedad, del papel que puede y/o debe cumplir en ella, de lo que puede esperar de los demás, así como de las herramientas con las que cuenta para enfrentar su vida ${ }^{1}$. De otro lado, el cuerpo humano no sólo es un "hecho" biológico:

1 Aquí se asocia el proceso de subjetivación con el concepto de habitus de Bourdieu. BOURDIEU, Pierre (2002). Razones Prácticas. Sobre la teoría de la acción. Barcelona: Anagrama.

* Magíster en Ciencia Politica. Profesor de la Universidad Pedagógica Nacional, Bogotá. juandepatmos1972@yahoo.com.mx 
Las concepciones que se forman del cuerpo humano (como el cuerpo mismo) son meollos receptores, ordenadores y proyectores de las esferas fisicas y sociales que las envuelven. El estudio de estas concepciones debe partir del conocimiento de estas sociedades que las crean y, recíprocamente, puede dar debida cuenta del mundo natural y social en que los creadores han vivido. La relación entre estas concepciones y la acción $y$ el entorno humano es tan intima, como se creyó en la antigüedad que era el vínculo entre el macrocosmos y el microcosmos (LÓPEZ, 1984; citado por Pinzón et ál, 2005).

El análisis de las concepciones de cuerpo, entonces, da cuenta de las sociedades que las originan. Asi por ejemplo, el 2 de enero de 1932, aparece en El Heraldo de Antioquia un anuncio publicitario promocionando una pasta dentífrica, a continuación se transcribe el texto del anuncio:

\section{¿Soportan sus dientes los dulces?}

Ud. está aficionada a los dulces. Hágalo $\sin$ cuidado, pero tenga Ud. precauciones que sus dientes no sufren [sic.]. Use Ud. por eso

\section{LA PASTA DENTRIFICA PEBECO.}

distinguida por su alto contenido de componentes activos y eficaces, con un sabor refrescante, seco e intenso (Payares y Arango, 1991, p. 262).

¿Cómo podemos leer la referencia al sexo femenino: "Ud. aficionada a los dulces. Hágalo sin cuidado", etc.? ¿Se trata de una distinción de género que reproduce imaginarios sobre el cuidado corporal: las mujeres requerian de una pasta dentifrica que les permitiera continuar con su afición a los dulces? ¿Para la publicidad de Medellin, los hombres no se entregaban a esta "debilidad"?

La oferta de salud oral en las primeras décadas del siglo XX giró sobre preceptos distintos a los que actualmente se ofrecen. En dicho momento se ofrecian cajas de dientes de lindos estilos, tratamientos sin dolor, pero también control del mal aliento, blanqueamiento y embellecimiento:
La última moda requiere que las damas se tiñan los dientes, de acuerdo con el traje y el temperamento del momento. Doña Gamby, en el grabado [que acompaña el texto que se transcribe aquil], pinta los dientes a Doña Bonner².

Actualmente, la oferta de atención odontológica se concentra en los aspectos estéticos: "[...] CLÍNICAS DENTALES. Su mejor elección. Tecnología láser. IMPLANTES. DISEÑO DE SONRISA. BLANQUEAMIENTO. ORTODONCIA. PROTESIS FIJA. ODONTOPEDIATRIA ${ }^{3 "}$. Pero la oferta estética más común, que hoy se asocia con la salud oral, no solo se relaciona con la ausencia de dolor o la prevención de las enfermedades, esta oferta se vincula con la promesa de éxito: "[Clínica dental] Construimos Sonrisas", "Diseño de sonrisa" (Ibid, p. 780). Son frecuentes las referencias publicitarias que prometen mayor aceptación social y laboral a través del diseño de la sonrisa. Como en los anuncios de las primeras décadas del siglo $X X$ que se han citado, la salud oral se sigue asociando con lo bello, pero a esta asociación inicial se articula la idea de que una sonrisa abre puertas y puede facilitar el éxito laboral. Las respuestas obtenidas en la IED permitirán profundizar sobre este tema. Los argumentos expuestos permiten comprobar algunos cambios en los esquemas de percepción, de visión y de división vinculados con la boca.

Ahora bien, usualmente los proyectos de educación en salud pretenden modificar comportamientos no saludables para producir otro tipo de comportamientos

El Heraldo de Antioquia. Mayo 14 de 1932. Citado por: Payares, Carlos y Alberto Arango. Consideraciones Sociohistóricas de la Odontología en Colombia y Antioquia. Siglo XX". Op. cit. p. 260.

3 Aviso tomado de PUBLICAR S.A (2007). Páginas Amarillas. Bogotá Publicar S.A., p. 770 . No se escribe el nombre de la clínica que ofrece sus servicios con este anuncio. que los expertos definen como saludables. No es este el lugar para describir en detalle esta lógica de acción, pero como se verá más adelante, el análisis del significado de la boca promueve una reflexión profunda sobre este tipo de dinámica.

\section{¿LE DARÍAS UN BESO A ALGUIEN QUE LE FALTARA UN DIENTE O QUE TUVIERA MAL ALIENTO?}

En el 2005, la Secretaria Distrital de Salud y el Hospital de Vista Hermosa desarrollaron el Área Demostrativa en Salud Oral. Con este proceso pretendieron diseñar estrategias educativas en salud oral dirigidas hacia los jóvenes, a partir de una comprensión más amplia de las concepciones que sobre la boca y la salud, despliegan los hombres y mujeres jóvenes (Hospital de Vista Hermosa-Secretaría Distrital de Salud, $2005)^{4}$. Este proyecto realizó una juiciosa crítica a varios modelos educativos en salud. Los resultados que se mencionan a continuación corresponden a la dinámica de investigación en la IED San Isidro. Alli se desarrollaron entrevistas para la producción participativa de un vídeo documental, así como 150 encuestas $^{5}$. Las encuestas recogen las observaciones realizadas durante la grabación del vídeo y se constituyeron

4 Documento redactado por: Sandra Milena Zuluaga, Luis Fernando Restrepo, John Jairo Uribe y Gabriel Jaime Otálvaro C. Bogotá, p. 4.

5 El estudio al que se hace referencia, describió las concepciones de la salud oral de hombres y mujeres jóvenes de Ciudad Bolivar. Para ello dinamizó la producción participativa de dos documentales en los que los jóvenes de dos grupos (escolarizados y no escolarizados) seleccionaron los temas, definieron el plan de grabación y adelantaron las grabaciones. Estos vídeos ofrecieron la oportunidad de adelantar entrevistas a profundidad y de diseñar la encuesta que a continuación se presenta. 
en un instrumento que dio cuenta de los principales aspectos de las concepciones sobre la boca y la salud oral.

La información obtenida no permite plantear generalizaciones estadísticas más allá de los limites de la localidad de Ciudad Bolívar. Sin embargo, para el presente artículo, se considera que las tendencias identificadas, así como el análisis de las entrevistas, permiten ilustrar la dinámica urbana frente a la concepción de la salud oral y por ende, plantear retos para la educación en salud. De otro lado, estos retos, algunos referentes conceptuales y las conclusiones a las que aqui se llegan. son elaboraciones posteriores al estudio mencionado.

Ante la pregunta "¿le darías un beso a alguien que le faltara un diente?" los entrevistados respondieron de dos formas: 1) negar el beso rotundamente y 2) dar el beso, pero si el diente que falta se perdió por un accidente. Los entrevistados aclararon que en ningún caso le darían un beso a alguien que hubiera perdido un diente a causa de una mala higiene.

Entrevistador: ¿Le darian un beso a alguien que le falta un diente?

Estudiante (hombre grado 11 - pareja): No. Porque me daria asco.

Ella: No. Eso es higiene. Tal vez si lo amara lo pensaria.

Estudiante (hombre grado 11): No le daria un beso a una mujer que le faltara un diente, me daría como vaina.

Entrevistador: ¿Vaina de qué, de que se le cayera un diente a usted?

Estudiante (hombre grado 11): No, porque yo los tengo amarrados [tiene brackets], no es un chiste. Eh, depende de por qué le falta un diente, si se lo quitaron, pues es una cosa, si se le pudrió u otra cosa similar, ya es otro cuento, entonces ya daría como más asco.

Ahora bien, la falta del diente permite que los entrevistados planteen alguna posibilidad, sin embargo el mal aliento es rechazado con unanimidad:
Entrevistador: ¿Le darian un beso a una persona que le faltara un diente?

Estudiante 1 (mujer grado 11): No.

Estudiante 2 (mujer grado 11): Lo pensaria.

Entrevistador: ¿Por qué?

Estudiante 2 (mujer grado 11): Porque podría ser yo.

Estudiante 1 (mujer grado 11): No sé.

Entrevistador: ¿Se ve feo?

Estudiante 1 (mujer grado 11): Sí

Entrevistador: ¿Si se ve feo no le das el beso?

Estudiante 1 (mujer grado 11): Pues no importa, la apariencia física no importa mucho.

Entrevistador: ¿Sí o no?

Estudiante 1 (mujer grado 11): No, pues no sé.

Entrevistador: ¿La apariencia física no importa mucho para ti (se refiere a la estudiante 2) y para ti (refiriéndose a la estudiante 1)?

Estudiante 1 (mujer grado 11): No. Tampoco.

Entrevistador: ¿Y si tuviera mal aliento?

Ambas: No.

Entrevistador: Ahí si no, ¿por qué?

Estudiante 2 (mujer grado 11): Falta de higiene, no sé.

De otro lado, los encuestados dividieron opiniones frente a la frase "Dientes feos no merecen besos". El $34 \%$ está completamente de acuerdo, el $18 \%$ parcialmente de acuerdo, el $22 \%$ ni de acuerdo ni en desacuerdo, el $9 \%$ parcialmente en desacuerdo y el $15 \%$ totalmente en desacuerdo. Puede decirse que esta distribución refleja el conjunto de consideraciones sentimentales que argumentan los entrevistados: puede tener dientes feos pero si es objeto de amor, recibirá besos.

En las explicaciones obtenidas se observa que, ante un cierto estado de la dentadura, se ponen en juego aspectos de su sensibilidad: el amor, las posibles circunstancias que enmarcan la pérdida de un diente, la incomodidad o el desaseo hacen parte de los imaginarios a tener en cuenta.

Entrevistador: ¿Tú le darias un beso a alguien que le faltara un diente?

Estudiante (mujer grado 9): ¡Uy, qué pregunta!. Pues qué, eso es importante, pero si quiero a la persona sí.

Entrevistador: ¿Le mandas a poner el diente?

Estudiante (mujer grado 9): SI, le mando a poner el diente. No mentiras, pues sí le daría un beso, si la quiero.

Entrevistador: ¿La llegarias a querer si le faltara un diente?

Estudiante (mujer grado 9): Si, porque lo que más vale es lo de adentro que lo de afuera.

Los entrevistados construyen sus argumentaciones en torno a la manera como lo que llaman el adentro se refleja en la dentadura. De una parte, la boca puede abrir o cerrar puertas, de otra, puede facilitar u obstaculizar relaciones afectivas. De este modo, cada uno intentará observar en la boca el reflejo de lo que cada quien es, pero al mismo tiempo intentará mostrar sus dientes de la mejor manera para lograr que los demás se hagan la mejor idea posible de él o ella ${ }^{6}$. A la pregunta "¿para usted es importante la boca?", los entrevistados insisten en que ella "da presencia".

Entrevistador: ¿Para Ud. Es importante la boca?

Estudiante (hombre grado 11): Si, porque le da presencia a la persona.

Entrevistador: ¿Qué es la presencia?

Estudiante (hombre grado 11): Refleja el aseo. Uno puede llegar a pensar

6 Este tipo de dinámicas, han sido analizadas por GofFMAN, Irving (1971). La presentación de la persona en la vida cotidiana. Buenos Aires: Amorrortu Editores. Sin embargo, para este autor, las escenificaciones cotidianas, son una derivación de la posición social, de modo que la participación de los actores en la construcción de las estructuras no es analizada. 
muchas cosas: uno se imagina si es desordenado, se puede imaginar la forma de ser. Si le falta un diente o tiene mal aliento, eso puede ayudar a formar el pensamiento hacia esa persona.

De otro lado, el $88 \%$ de los entrevistados plantearon que los dientes perfectos para una persona son "muy importantes" (Gráfico 1). Como resultado de lo anterior, la "construcción de una sonrisa" no sólo es una estrategia publicitaria, sino que se constituye en un proceso de subjetivación, de elaboración de la autoimagen, así como en una estrategia para desarrollar formas de socialización.

La boca da cuenta de la "presencia de una persona". Esa presencia permite que los demás se formen una idea de quién es el observado y cómo es. Esta idea, se asocia a la formación, a la posibilidad de obtener un empleo, de lograr el éxito, de construir una relación de pareja.

Estudiante (mujer-grado 11): No sé, es como el reflejo de una persona, uno le ve la cara y si le falta un diente uno dice 'juichhi'. En cambio si tiene la dentadura bonita, pues es diferente, refleja lo que él es. Si tiene una dentadura bonita es que se cuida más en su aspecto personal. Eso es importante porque refleja los principios que le dan en su casa: si es sucio pues imagínese cómo tendrá los dientes, si es limpio refleja lo que le han enseñado en su casa

La boca, es pues un reflejo, no sólo de la casa, sino que es fundamental para obtener la aprobación de los demás. Esa presencia habla, hace que los demás se refieran de un modo $u$ otro hacia la persona que se presenta a través de su dentadura. El $51 \%$ de los encuestados está completamente de acuerdo, con la afirmación "Para ser joven de éxito debes tener una dentadura bonita" (Gráfico 2). Asi que el éxito se encuentra asociado en una medida no despreciable con la "presencia" y esta presencia se asocia a la imagen que proyecta la sonrisa.

\section{GRÁFICO 1:}

IMPORTANCIA QUE OTORGA A LOS DIENTES PERFECTOS UNA PERSONA

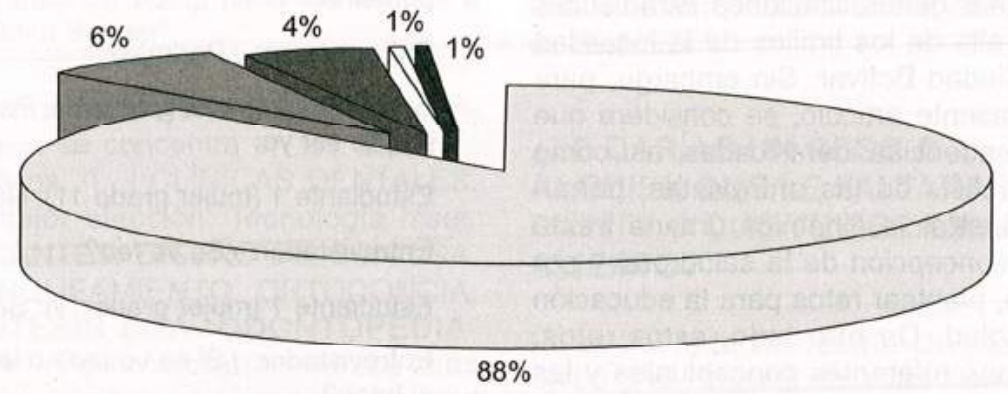

Muy importante $88 \%$

No le importa $1 \%$

Poco importante $6 \%$

NR $1 \%$

Le es indiferente $4 \%$

\section{GRÁFICO 2}

PARA SER JOVEN DE ÉXITO DEBES TENER UNA BONITA DENTADURA
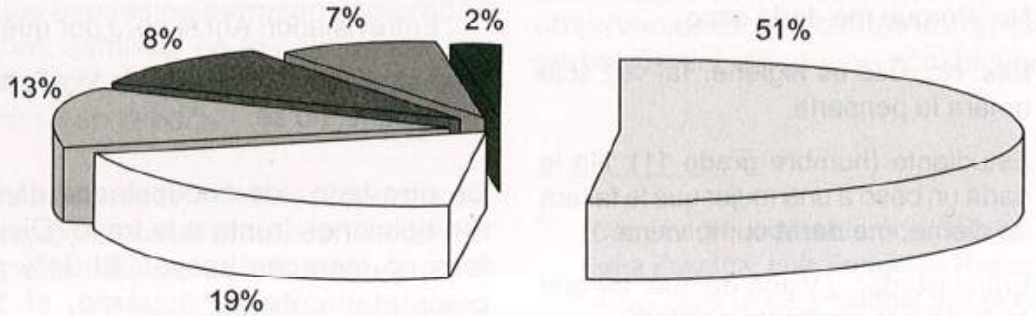

Completamente de acuerdo $51 \%$

Parcialmente en desacuerdo $8 \%$

Parcialmente de acuerdo $19 \%$

Totalmente en desacuerdo $7 \%$

Ni de acuerdo ni en desacuerdo $13 \%$
NR $2 \%$ 


\section{La dentadura habla de cada uno:}

Entrevistador: O sea, para ustedes la boca es importante ¿por qué?

Estudiante 1 (mujer grado 11): Porque es una forma de presentación de uno.

Estudiante 2 (mujer grado11): Dice mucho.

Entrevistador: Qué dice, si le llega a faltar un diente o tiene mal aliento ¿qué dice?

Estudiante 2 (mujer grado11): Pues que es falta de higiene, es descuido.

Entrevistador: ¿Ustedes catalogan a las personas por la apariencia de los dientes?

Ambas: No.

Entrevistador: Ustedes dicen que se cepillan los dientes por la salud

Estudiante 2 (mujer grado11): Y por la presentación personal.

Entrevistador: ¿Y por qué por la presentación personal?

Estudiante 1 (mujer grado11): Por ejemplo, para una entrevista de trabajo, está hablando uno y qué tal uno con el aliento de uno ahi todo feo...

Estudiante 2 (mujer grado11): Desagradable...

Estudiante 1 (mujer grado11): Sí, desagradable. Para todo es importante, para el trabajo, en cualquier lugar, para uno mismo es fastidioso, hasta para uno mismo puede fastidiarle ese mal olor.

Entrevistador: ¿Ustedes se fijan en la boca de la gente?

Ambas: Sí.

Entrevistador: ¿Y hablan con sus compañeros de eso?

Estudiante 2 (mujer grado11): A veces, uno habla y comenta 'vea que tal persona...' y eso.

Entrevistador: ¿Ustedes chismosean sobre la boca de los demás?

Estudiante 1 (mujer grado11): Pues no siempre, no tanto.

Estudiante 2 (mujer grado11): A veces.
Por todo lo anterior, no sorprende que el $81 \%$ de los encuestados se encuentren completamente de acuerdo con la afirmación "La sonrisa es la carta de presentación de una persona". Queda claro que el cuidado de los dientes no se deriva sólo de la preocupación por el dolor o la enfermedad que su descuido puede provocar. Dicho cuidado se vincula con las estrategias que los actores despliegan para obtener algunos de sus objetivos: empleo, aceptación en un grupo de amigos, novio, novia, etc.

Estudiante (mujer grado 11): Los dientes son importantes porque con ellos podemos ayudar a ingerir la comida y si no se tiene cuidado después uno va tener problemas para comer, o algo asi.

Entrevistador: O para que le den besos.

Estudiante (mujer grado 11): Si también.

Entrevistador: ¿Crees que las personas se cuidan los dientes sólo por apariencia, por la estética?

Estudiante (mujer grado 11): No, también por salud.

Entrevistador: ¿Y la salud y la apariencia son opuestos?

Estudiante (mujer grado 11): No de pronto no, porque en la salud uno tiene que estar bien, y para estar bien hay que tener una buena apariencia, son dos cosas muy importantes.

Entrevistador: ¿O sea que la salud y la apariencia van de la mano?

Estudiante (mujer grado 11): Si, puede ser.

Pero esta lógica no es completamente homogénea. Aqui cabe la cuestión de la correspondencia entre lo interno y lo externo.

Entrevistador: ¿Qué piensan de la frase "la apariencia refleja lo de adentro"?

Estudiante 1: No estoy de acuerdo.

Estudiante 2: Puede ser que uno tenga los dientes feos y puede tener una personalidad agradable, mientras que otra tenga los dientes bonitos y ser desagradable.
La relación entre lo bello y lo bueno, o dicho de otro modo, entre la salud (lo bueno) y la apariencia (lo bello), se constituye en un núcleo de especial interés en la concepción corporal juvenil. De un lado, la salud puede ir de la mano con la presencia, y por esta vía, con una noción de disfrute de la vida (un tipo de vínculo especifico de lo bueno y lo bello), del otro, la salud sigue articulándose a los lenguajes de los deberes ${ }^{7}$ y por esta vía, con un modo de distanciar lo bueno y lo bello, esto es, de la desarticulación entre las posibles formas de disfrutar de la vida. Por todo lo anterior, el desarrollo de actividades educativas en salud que pretendan sustituir unos comportamientos no-saludables por otros considerados como saludables, quedan en el vacio, en tanto que no consideran estas formas de "lectura" de lo saludable.

La salud, en tanto producción y/o control del comportamiento, tal y como se concibe bajo la idea de los "hábitos saludables", puede entonces, partir de las asociaciones juveniles entre lo agradable y lo saludable, o insistir en la contradicción de estas dos nociones: lo que es saludable no es agradable. Como se verá a continuación, ambas opciones han sido institucionalizadas en el transcurso de la historia reciente de Colombia, de ahi la importancia de este ángulo para repensar la educación en salud.

\section{EN LA BOCA DE TODOS: RETOS PARA LA EDUCACIÓN EN SALUD}

La relación entre lo agradable y lo saludable, temas en los que insistieron los entrevistados, se vinculan con proyectos sociohistóricos de país. Del análisis de esta relación, se derivan algunos retos para la educación en salud. En esta dirección, vale la pena referirse a las imágenes sobre la familia y sobre los

7 Como puede denunciarse en los refranes que aluden a que todo lo bueno, engorda o hace daño, o en los chistes que refieren que el médico le quita al paciente todo lo que le gusta. 
individuos que se han propuesto en la historia reciente de Colombia. Mientras a inicios del siglo XX, la higiene propugnaba por la construcción de cuerpos idóneos para el trabajo fabril, el surgimiento de nuevas sensibilidades e intereses, ha demandado otras subjetividades, tanto la capacidad de producir en forma competitiva, como de consumir de forma responsable (CADENA, 2004). Así, las imágenes sobre el cuidado del cuerpo en los albores del siglo XX, insisten en la disciplina:

Los niños deben ser sometidos a una educación racional, que tenga por efecto detener el desarrollo de sus disposiciones morbosas, al menos neutralizarlas en cuanto sea posible. Las tendencias emotivas y neuropáticas se combatirán con un trabajo físico bien dirigido, gimnástica, ocupaciones materiales, vida activa y en cuanto se pueda, al aire libre ${ }^{8}$.

Estas imágenes, no sólo traducen las actitudes de los especialistas de la época hacia los niños, sino que se articulan a la dinámica de administración de la familia:

Ya fuera individual o colectivamente, con propósitos físicos o emocionales, la familia ha sido un espacio fundamental para la acción estatal y social a lo largo de todo el siglo XX. El gobierno de la población se ha apoyado permanentemente en la administración biopolítica de la familia y, a través de ella, ha buscado formar individuos capaces de garantizar el funcionamiento adecuado de la vida en sociedad. Las imágenes de padres, madres e hijos han sido creadas a través de saberes expertos, de instancias gubernamentales y de instituciones transnacionales, todas interesadas en masificar una idea de familia ideal, necesariamente ligada a la sociedad ideal (lbid).

8 Anzola, (1904). Citado por Roselli, Humberto (1968). Historia de la Psiquiatria en Colombia. Tomo II. Bogotá: Editorial Horizontes. Este texto es citado a su vez por Cadena, Ana Maria. Proyectos sociopoliticos, poblacionales y familias: de las politicas de higiene al control a través del afecto. Colombia 1900-1999. Op. Cit. p. 22.
La disciplina, entonces, se constituyó en referente esencial para la consolidación de la nación durante la primera parte del siglo XX:

La industria en nuestro país proporcionaria una gran moralidad, nos daria medios suficientes para una vida honesta; sería una prevención insuperable para el crimen y el ocio?.

Sin embargo, a la disciplina en el trabajo, se ha sumado el consumo del entretenimiento, así como el surgimiento de una sociedad postindustrial, en la que la producción gira cada vez menos en torno a la fabricación de cosas, y se orienta más hacia la denominada "producción inmaterial", esto es, producción de ideas, imágenes y afectos (HART y NEGRI, 2000). En este escenario, las habilidades del sujeto, deben cambiar:

El sujeto como productor debe ser capaz de reprimir y diferir la gratificación inmediata de sus deseos y cultivar una ética del trabajo; como consumidor debe dejarse llevar por el deseo y ceder ante sus impulsos, buscar la satisfacción constante e inmediata, ceder permanentemente a la tentación (...) Por un lado se censuran los excesos y todo lo que anule la capacidad productiva, por el otro, se subraya la importancia del deseo y del placer inmediato, del consumo irrestricto ${ }^{10}$.

Al parecer, el vínculo entre el adentro y el afuera, asi como la relación entre buena salud y el goce de la vida, responden a esta perspectiva: lo emotivo se ha articulado con el consumo de la diversión. De ahí que pueda decirse que los resultados obtenidos en Ciudad Bolivar, ilustren la situación en Bogotá (aún cuando sea necesario desarrollar estudios más amplios).

"¿Le darías un beso a alguien que le falta un diente?" Esta cuestión representa hoy un asunto que traduce la organización social, la tensión entre lo

9 Garcia Navas, Josué (1948). Citado por Cadena, Ana María. Óp. Cit.

10 Medina Cano (1998). Citado por Cadena, Ana María. Óp. Cit. 24 que se ve y lo que se es, pero también la angustia entre las posibilidades de éxito y de fracaso. Por un lado, lo saludable se vincula con el goce: sentirse bien y verse bien son elementos indisociables. Por otro lado, verse bien es tanto un requisito de la competitividad (laboral y afectiva), como un aspecto del consumo. ¿Qué retos plantean estas evidencias a la educación en salud? ¿Es suficiente que se despliegue una educación en salud que sólo busque promocionar comportamientos adecuados desde la perspectiva de los técnicos y científicos? Las respuestas de los estudiantes ofrecen varios retos para la educación en salud. Los retos pueden sintetizarse de la siguiente manera:

- La necesidad de entender la educación en salud como proceso de construcción de subjetividades. No basta con la producción de comportamientos saludables, se requiere establecer la manera como dichos comportamientos saludables se relacionan con el sentido general que cada actor construye sobre su vida y su sociedad.

- Como consecuencia de lo anterior, la necesidad de analizar los procesos culturales en los que las acciones de salud se inscriben y los efectos que dichas acciones traen consigo. En otras palabras, establecer los modos de recepción de las propuestas educativas en salud y, al mismo tiempo, comprender las maneras como esos procesos de recepción pueden o no desarrollar transformaciones en el entramado de significaciones, sentidos y usos cotidianos.

- Las estrategias educativas deben dar cuenta de las implicaciones sociopoliticas que sus proyectos traen consigo: ¿qué tipo de corporalidad se reproduce a través de las dinámicas de educación en salud? Y por ende ¿qué tipo de orden social se reproduce a través de la educación en salud?

El análisis desarrollado permite plantear que las perspectivas sobre lo saludable, derivan en, y se derivan de, proyectos sociopoliticos generales. En consecuencia, se puede definir la educación en 
salud como un esfuerzo por incidir en las concepciones de cuerpo y en las estrategias sociales de grupos especificos.

Por último, recordar que el mundo occidental ha construido diversas relaciones entre el "adentro" y el "afuera": "Básicamente su problemática inicial se centra en lo que el mundo occidental ha dado en llamar el alma humana: principio vital, vector de inteligencia, candidato para la salvación y condena". Los hombres y mujeres jóvenes actualizan este dualismo a través de sus reflexiones sobre la boca: "Esta alma humana, incluso inmaterial para algunos, puede no obs- tante ser contenida dentro de un cuerpo de hombre, se expresa a sí misma en su cara y se da a conocer en sus gestos" (FECHER, 1990, p. 14). Por todo lo expuesto hasta ahora, vale la pena preguntarse de nuevo ¿le darías un beso a alguien que le falta un diente.

\section{REFERENCIAS}

Bourdieu, Pierre. (1998). La Distinción. Madrid: Taurus.

Bourdieu, Pierre. (2003). Cuestiones de Sociologia. Madrid: Ediciones Istmo.

Bourdieu, Pierre. (2002). Razones Prácticas. Sobre la teoría de la acción. Barcelona: Anagrama.

Cadena, Ana Maria. (2004). Proyectos sociopolíticos, poblacionales y familias: de las políticas de higiene al control a través del afecto. Colombia 1900-1999. Documentos CESO No. 76. Centro de Estudios Socioculturales e internacionales, CESO. Bogotá: Universidad de los Andes.

GofFMAN, Irving. (1971). La presentación de la persona en la vida cotidiana. Buenos Aires: Amorrortu Editores.

FECHER, Michel. (1990). Introducción. En Michel Fecher; Ramona Naddaff y Nadia Tazi (eds.). Fragmentos para una historia del cuerpo humano. Parte primera. Madrid: Editorial Taurus.

Foucault, Michel. (2000). Defender la sociedad. Fondo de Cultura Económica. Buenos Aires.
HART, Michael y NEGRI, Toni. (2000). Imperio. Bogotá: Ediciones Desde Abajo.

Hospital de Vista Hermosa-Secretaria DisTRITAL DE SALUd. "Construir futuros posibles con los jóvenes en Bogotá. Una aproximación a los mundos juveniles desde el sector salud, para la construcción de estrategias de interacción para enfrentar las necesidades sociales". Bogotá, 2005.

MEAD, Margaret. (1977). Cultura y Compromiso. El mensaje a la nueva generación. Barcelona: Granica.

Pedraza, Zandra. (2001). Sentidos, movimiento y cultivo del cuerpo: política higiénica. En: Martha Cecilia Herrera y Carlos Filmar Díaz (comp.). Educación y Cultura Politica: Una mirada multidisciplinaria. Bogotá: Universidad Pedagógica Nacional-Plaza y Janés.

Payares, Carlos y Arango, Alberto. (1991). Consideraciones Sociohistóricas de la Odontología en Colombia y Antioquia. Siglo XX". Medellin: Promotora de Ediciones y Comunicación S.A.
Peralta, Victoria. (1995). El ritmo lúdico y los placeres en Bogotá. Bogotá: Editorial Planeta.

PINZÓN, Carlos; SUÁREZ, Rosa y GARAY, Gloria. (2005). Mundos en red. La cultura popular frente a los retos del siglo XXI. Bogotá: Universidad Nacional de Colombia.

Prost, Antonie. (1992). Fronteras y espacios de lo privado. En: George Duby y Philippe Aries (dirs.). Historia de la Vida Privada. La vida privada en el siglo XX. Tomo 9. Taurus.

Publicar S.A. (2007). Páginas Amarillas. Bogotá: Publicar S.A.

URIBE, John Jairo. (2001). La Invención de lo Juvenil. Programa Desarrollo Institucional y comunitario, Programa de Cooperación Internacional Unión Europea-República de Colombia. Bogotá. 